\title{
Double-outlet right ventricle revisited
}

\author{
Ameneh Ebadi, DO, ${ }^{a}$ Diane E. Spicer, BS, ${ }^{a}$ Carl L. Backer, MD, ${ }^{b}$ F. Jay Fricker, MD, ${ }^{a}$ and \\ Robert H. Anderson, MD, BSc, FRC Path
}

\begin{abstract}
Objectives: Double-outlet right ventricle is a form of ventriculoarterial connection. The definition formulated by the International Society for Nomenclature of Paediatric and Congenital Heart Disease is based on hearts with both arterial trunks supported in their greater part by a morphologically right ventricle. Bilateral infundibula and ventricular septal defects are highly debated criteria. This study examines the anatomic controversies surrounding double-outlet right ventricle. We show that hearts with double-outlet right ventricle can have atrioventricular-to-arterial valvular continuity. We emphasize the difference between the interventricular communication and the zone of deficient ventricular septation.
\end{abstract}

Methods: The hearts examined were from the University of Florida in Gainesville; Johns Hopkins All Children's Hospital, St Petersburg, Fla; and Lurie Children's Hospital, Chicago, Ill. Each specimen had at least $75 \%$ of both arterial roots supported by the morphologically right ventricle, with a total of 100 hearts examined. The morphologic method was used to assess anatomic features, including arterial-atrioventricular valvular continuity, subarterial infundibular musculature, and the location of the hole between the ventricles.

Results: Most hearts had fibrous continuity between one of the arterial valves and an atrioventricular valve, with bilateral infundibula in $23 \%$, and intact ventricular septum in $5 \%$.

Conclusions: Bilateral infundibula are not a defining feature of double-outlet right ventricle, representing only $23 \%$ of the specimens in our sample. The interventricular communication can have a posteroinferior muscular rim or extend to become perimembranous (58\%). Double-outlet right ventricle can exist with an intact ventricular septum. (J Thorac Cardiovasc Surg 2017;154:598-604)

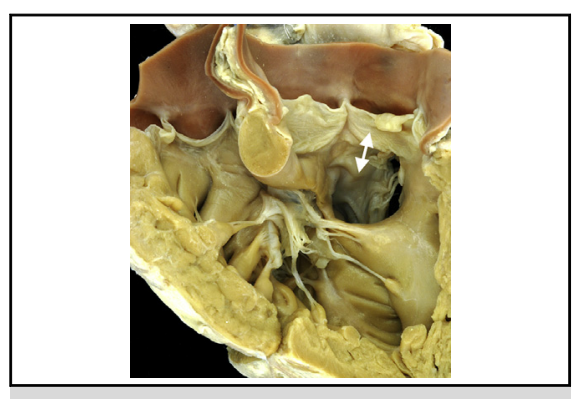

Fibrous continuity between an atrioventricular valve and an arterial valve.

\section{Central Message}

Hearts with double-outlet right ventricle show notable variation in infundibular morphology, with fewer than one-quarter of the specimens in our sample having bilateral coni.

\section{Perspective \\ There is significant morphologic variation within double-outlet right ventricle. The key debated anatomic feature for the diagnosis is presence of bilateral infundibula. In our study, only 23 of 100 specimens possessed bilateral infundibula. It should not be used as a neces- sary criterion for diagnosis, and its previous requirement may have underestimated the inci- dence of double-outlet right ventricle.}

See Editorial Commentary page 605.
When describing the surgical anatomy of hearts with double outlet from the right ventricle in the setting of concordant atrioventricular connections, Wilcox and colleagues ${ }^{1}$ commented that through the years, ongoing analyses of the hearts included or not included within this entity could be seen as the investigators taking one step forward and two steps back in their search for understanding and consensus. Little has changed in the 30 years that have passed since this

From the ${ }^{\mathrm{a}}$ University of Florida Health Congenital Heart Center, Gainesville, Fla; bepartment of Cardiothoracic and Vascular Surgery, Lurie Children's Hospital, Chicago, Ill; and ' Institute of Genetic Medicine Newcastle University, Newcastle-upon-Tyne, United Kingdom.

Received for publication March 21, 2016; revisions received Feb 13, 2017; accepted for publication March 16, 2017; available ahead of print May 18, 2017.

Address for reprints: Ameneh Ebadi, DO, 13525 Nemours Pkwy, Orlando, FL 32827

(E-mail: Ameneh.Ebadi@nemours.org).

0022-5223/\$36.00

Copyright (c) 2017 by The American Association for Thoracic Surgery

http://dx.doi.org/10.1016/j.jtcvs.2017.03.049 investigation. ${ }^{1}$ The definitions formulated by the combined committees of the Society of Thoracic Surgeons and the European Society of Cardiothoracic Surgery ${ }^{2}$ were based on inclusion of hearts in which both arterial trunks, in their greater part, were supported by right ventricular structures. This committee accepted that the presence of bilateral infundibula was not an essential criterion for diagnosis. ${ }^{2}$ Lacour-Gayet and colleagues, ${ }^{3}$ nonetheless, although accepting the basic definitions that accepted the value of the " $50 \%$ rule," argued that "the presence of a subaortic conus...remains the major landmark of this anomaly." They also noted, "Lecompte has proposed to change the

Scanning this QR code will take you to the article title page.

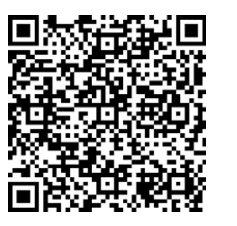




\section{Abbreviation and Acronym \\ $\mathrm{DORV}=$ double-outlet right ventricle}

term DORV for malposition of the great arteries." ${ }^{3}$ Those investigating this entity, furthermore, typically describe the hole between the ventricles, which provides the exit from the left ventricle, as a "ventricular septal defect." Most also describe its location following the precedent set by Lev and colleagues. ${ }^{4}$ Because the hole is the primary exit from the left ventricle, however, it would be a disaster for the defect to be closed surgically, although such closure is the usual therapeutic approach for most other channels described as representing ventricular septal defects. With these continuing contradictions in mind, we have revisited several series of autopsied hearts, selecting for study hearts in which both arterial trunks arose in their greater parts from the morphologically right ventricle. We hoped to shed further light on the controversies that continue to surround this group of congenital cardiac malformations.

Our aims were threefold. In the first place, we sought to establish whether hearts with atrioventricular-to-arterial valvular continuity can exhibit so-called " $200 \%$ double outlet." In the second place, we aimed to show that the roof of the interventricular communication in the setting of $200 \%$ double outlet can either be made up of the muscular ventriculoinfundibular fold or else be formed by fibrous continuity between the leaflets of the atrioventricular and arterial valves. Finally, and perhaps most importantly, we aimed to emphasize the difference between the interventricular communication and the area of deficient ventricular septation. In passing, we also show that hearts can exist with both arterial trunks arising from the right ventricle in the setting of an intact ventricular septum.

\section{MATERIALS AND METHODS}

The 100 hearts examined were drawn from the archives held at University of Florida in Gainesville, Fla; Johns Hopkins All Children's Hospital in St Petersburg, Fla; and Lurie Children's Hospital in Chicago, Ill. For each individual heart, we established the arrangement of the atrial appendages and the type of atrioventricular connection. We determined whether the atrioventricular junctions, if two were present, were separate from one another, or whether the junctions were part of a common entity. We noted whether one or the other atrioventricular junction was absent. We included in our study all hearts encountered in the archives in which at least three-quarters of the circumferences of both arterial roots was supported by the morphologically right ventricle. When there was overriding of one or the other arterial root, or of both roots, we assessed the extent of override by determining the location of the cord subtended by the short axis of the muscular apical ventricular septum relative to the orifice of the overriding valve (Figure 1, $A$ ). We used this feature of the commitment as judged in the short axis, rather than taking the angulation of the long axis of the apical muscular septum as our guide, because we reasoned that our chosen measurement was less likely to change during life according to the different phases of the cardiac cycle. Having used this feature to select our hearts, we then assessed the location of the hole between the ventricles relative to right ventricular landmarks, the presence or absence of arterial-to-atrioventricular valvular continuity, the nature of the subarterial infundibular musculature, the structure and attachments of the outlet septum, and the positions and relationships of the arterial trunks as they exited the heart and extended into the mediastinum. We also made a list of associated anomalies in each of the individual hearts.

\section{RESULTS}

As determined by the morphology of the atrial appendages, most of the hearts had usual atrial arrangement; however, 9 had isomeric right atrial appendages and
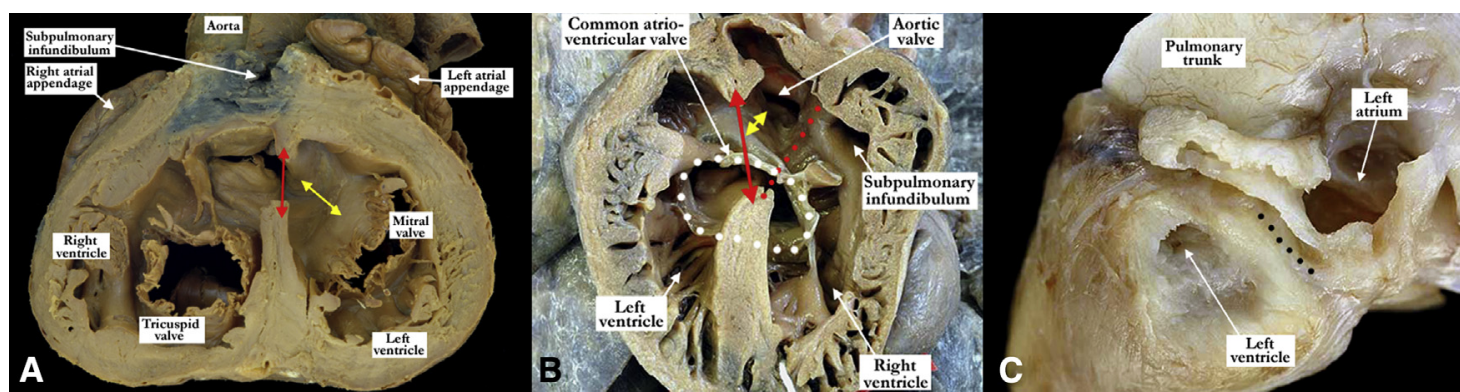

FIGURE 1. A, The heart shown has been sectioned along the short axis of the ventricular mass and is photographed from the apex looking toward the base. There are separate atrioventricular junctions and overriding of the aortic root, with the pulmonary root supported by the right ventricle. The line representing the cord of the apical muscular septum (double-headed red arrow) shows that the larger part of the aortic root is also supported by the right ventricle, showing in turn that the ventriculoarterial connection is one of double outlet, despite the fact that there is fibrous continuity between the leaflets of the aortic and mitral valves (double-headed yellow arrow). Note the plane of cleavage between the orifice of the mitral valve and the inferior part of the muscular ventricular septum. B, Short axis cut of a heart with common atrioventricular junction (dotted white oval), with the junction overriding the crest of the apical muscular ventricular septum. The cord of the septum relative to the arterial roots (double-headed red arrow) again shows the presence of double-outlet right ventricle, despite the presence of fibrous continuity between the leaflets of the common valve and the aortic valve (double-headed yellow arrow). The red dotted line shows the area of putative septation. This heart has left-handed topology, with a left-sided right ventricle and a right-sided left ventricle. C, The posterior aspect of a heart with double outlet from the right ventricle but with absence of the left atrioventricular connection. The left atrioventricular groove (black dots) interposes between the floor of the left atrium and the incomplete left ventricle, which is made up exclusively of its apical trabecular component. Both arterial trunks arise exclusively from the morphologically right ventricle (not shown). 


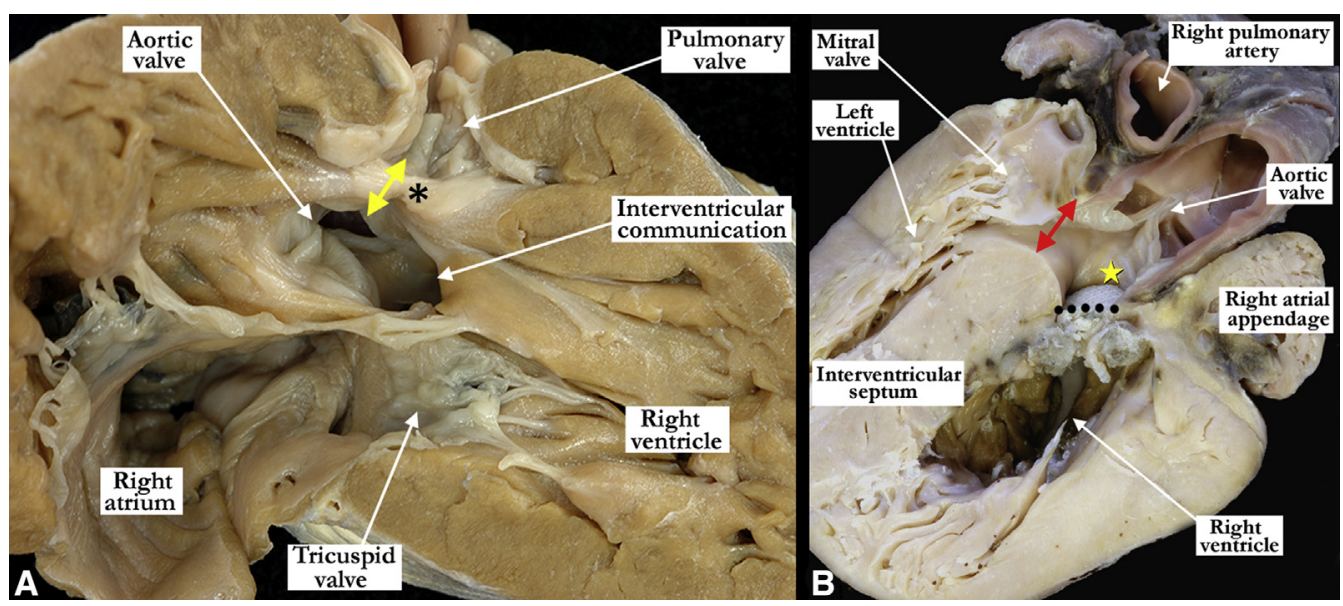

FIGURE 2. A, A heart with double-outlet right ventricle and a fibrous outlet septum (asterisk), as seen from the right ventricle. There is fibrous continuity in the roof of the interventricular communication between the leaflets of the aortic and pulmonary valves (double-headed yellow arrow). The interventricular communication, which is doubly committed, opens to the right ventricle between the limbs of the septomarginal trabeculation, or septal band. B, The heart has been sectioned in four-chamber fashion, and the anterior part of the heart is shown as viewed from behind. The patient had undergone tunneling of the interventricular communication to the aortic root, with the patch inserted by the surgeon remaining in place (black dotted line). The patch marks the site of deficient ventricular septation and is separate from the plane of the geometric interventricular communication (double-headed red arrow). The latter plane is roofed cranially by the inner heart curvature. The yellow star shows the outlet septum, which is muscular in this heart.

3 had isomeric left atrial appendages. Most also had separate atrioventricular junctions, guarded by mitral and tricuspid valves (Figure 1, A). In 16 hearts, nonetheless, there was a common atrioventricular junction guarded by a valve with a common orifice (Figure 1, B). In 9 hearts, the left-sided atrioventricular connection was absent (Figure 1,C). In all the hearts with separate atrioventricular junctions, a plane of cleavage was seen between the mitral valve and the ventricular septum. Because of this, no part of the muscular ventricular septum interposed between the inlets of the left and right ventricles. The inlet of the right ventricle extended significantly inferiorly relative to the site of union between the muscular ventricular septum and the inferior atrioventricular junction (Figure 1). Only in the setting of common atrioventricular junctions (Figure 1, B) was the muscular ventricular septum interposed between the two ventricular inlets.

In all the hearts examined with holes between the ventricles, the plane of the interventricular communication was fundamentally different from the area needing to be closed, so that it directed blood from the left ventricle to one or other of the arterial trunks. This latter area, which corresponds to the area of putative ventricular septation as seen in the developing heart, extends from the crest of the apical muscular septum to the under surface of the muscular outlet septum, or its fibrous remnant in 6 of the hearts (Figure 2, A). It is the area closed by the surgeon to connect the left ventricle to one or other of the arterial roots (Figure 2, B). Depending on the attachments of the outlet septum, when it was muscular, the interventricular communication, which opens to the right ventricle between the limbs of the septomarginal trabeculation, or septal band, could be located in either subaortic or subpulmonary position. In those hearts with subaortic defects, the cranial end of the outlet septum was attached to the muscular ventricular septum adjacent to the cranial limb of the septomarginal trabeculation (Figure 3, A). In the setting of subpulmonary defects, in contrast, the caudal attachment of the outlet septum joined the muscular inner heart curvature directly above the caudal limb of the septomarginal trabeculation (Figure 3, B). In the hearts with subaortic defects, the aortic root was posteriorly located, and the arterial trunks themselves spiraled as they extended into the mediastinum. In contrast, the aortic root was anterior when the defect was subpulmonary, and the arterial trunks were parallel rather than spiraling. In the hearts with fibrous outlet septa, there was fibrous continuity between the leaflets of the aortic and pulmonary valves. In these hearts, therefore, the interventricular communication was doubly committed (Figure 2, A). In the hearts with common atrioventricular junction, the interventricular communication was located between the ventricular inlets, meaning that it was not committed directly to either of the arterial roots (Figure 4, A). Some of the defects embedded within the musculature of the ventricular septum could also be distant from both arterial roots and therefore were considered noncommitted (Figure 4, B). In 5 hearts, however, the ventricular septum was intact (Figure 4,C).

Most hearts had fibrous continuity between the leaflets of one of the arterial valves and an atrioventricular valve (Figure 3, $A$ and $B$ ), with only 23 hearts possessing completely muscular infundibula bilaterally 


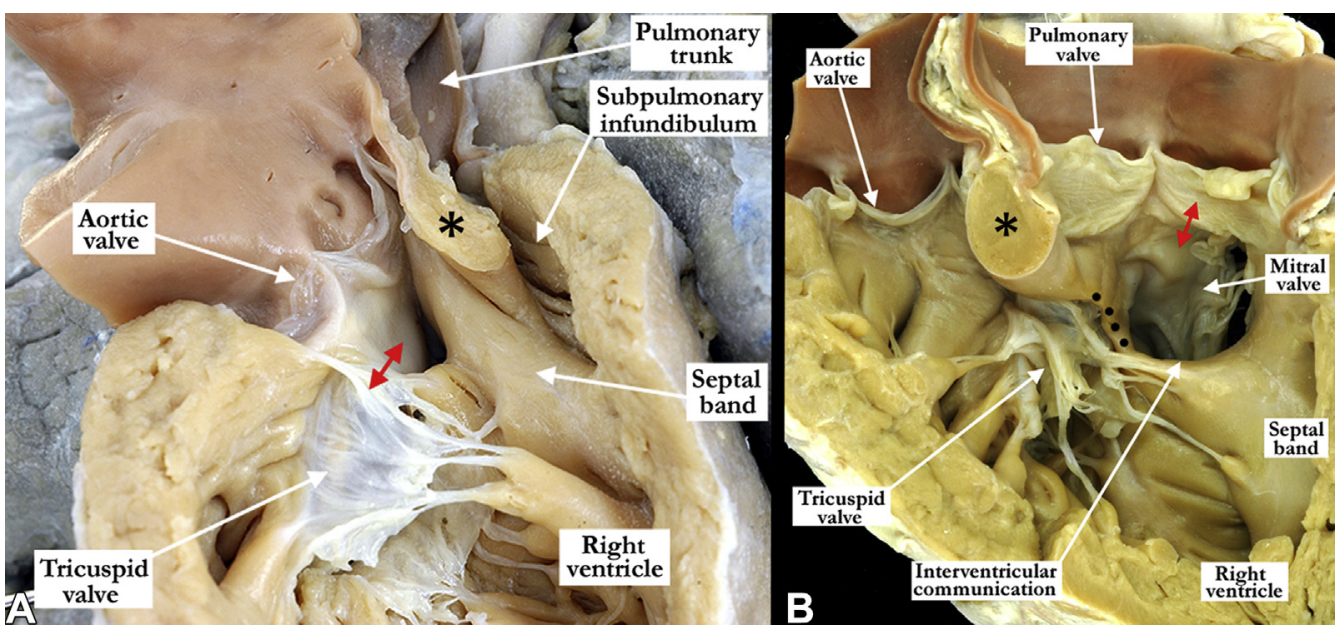

FIGURE 3. A, This heart has a muscular outlet septum (asterisk) that is attached to the cranial limb of the septomarginal trabeculation, thus committing the interventricular communication to the aortic root. Note the presence of fibrous continuity between the leaflets of the mitral and tricuspid valves (double-headed red arrow); this feature makes the defect perimembranous. Note also the narrowed subpulmonary infundibulum. B, The muscular outlet septum (asterisk) is attached to the caudal limb of the septomarginal trabeculation or septal band, committing the interventricular communication to the pulmonary trunk. There is fibrous continuity in the roof of the defect between the leaflets of the mitral and pulmonary valve (double-headed red arrow). A muscle bar (black dots), however, interposes posteroinferiorly between the leaflets of the pulmonary and tricuspid valves. The aortic valve is supported by a completely muscular infundibulum.

(Figure $4, A$ and $B$ ). Even in some of the hearts with muscular walls interposing between the leaflets of both arterial valves and the atrioventricular valves, there was fibrous continuity between the leaflets of the aortic and pulmonary valves (Figure 2, A). In these latter hearts, the separate subarterial infundibula were therefore not complete. Of the 58 hearts with bilaterally incomplete muscular infundibula, 29 showed continuity between the leaflets of the aortic and mitral valves, 11 had fibrous continuity between the leaflets of the pulmonary and mitral valves, and 9 had continuity between the leaflets of a common atrioventricular valve and the aortic valve. In most hearts with separate atrioventricular junctions, there was also fibrous continuity between the leaflets of the tricuspid and mitral valves (51 of 75 hearts). In these hearts, the interventricular defects were therefore perimembranous, because the area of fibrous continuity incorporated the atrioventricular component of the membranous septum (Figure 5, A). In 17 hearts, nonetheless, the ventriculoinfundibular fold separating the leaflets of the arterial and atrioventricular valves fused with the caudal limb of the septomarginal trabeculation, thus producing a muscular bar that protected the axis of

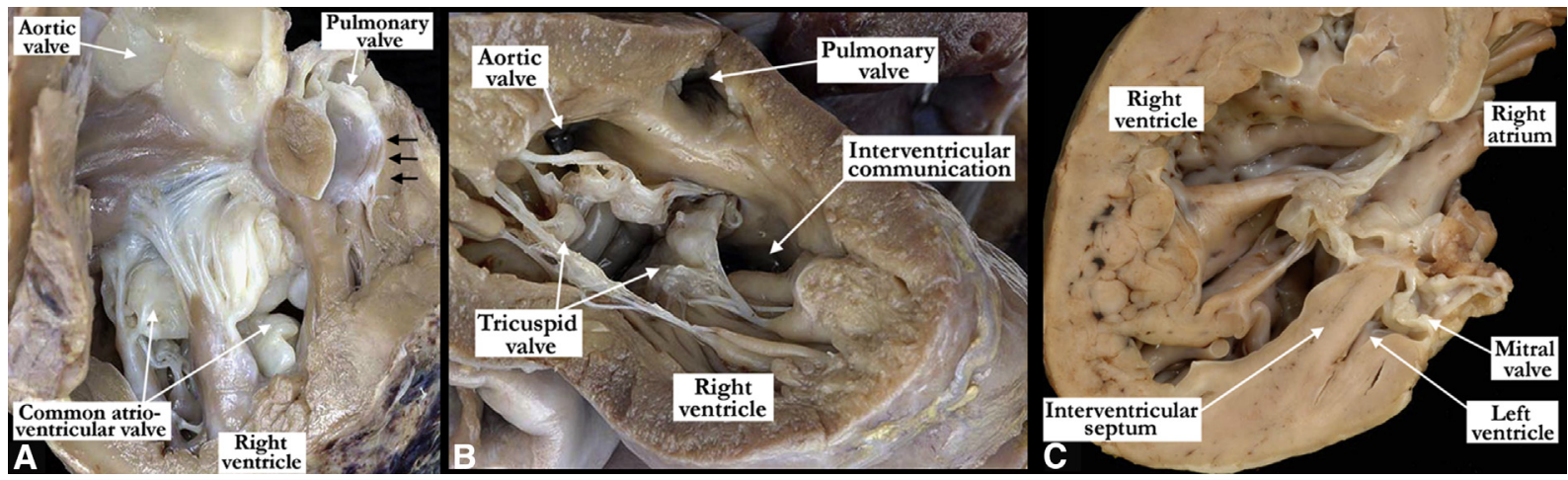

FIGURE 4. A, Heart with double-outlet right ventricle with bilateral infundibula and common atrioventricular junction. The ventricular component of the atrioventricular septal defect is distant from the arterial roots. Our examination suggests that it might have been possible to channel the defect to either arterial outlet by construction of an extensive intraventricular baffle, although we cannot be sure of this observation. Note the presence of the narrowed subpulmonary infundibulum (black arrows). B, Heart with an interventricular communication embedded within the inferior part of the muscular ventricular septum. This defect has the tension apparatus of the tricuspid valve interposed between its opening and both arterial roots, making it noncommitted. C, Heart prepared by making a four-chamber cut, with the anterior part of the heart shown as viewed from the posterior aspect. The muscular ventricular septum is intact. The mitral valve is imperforate. Both arterial trunks arise from the morphologically right ventricle (not shown). 


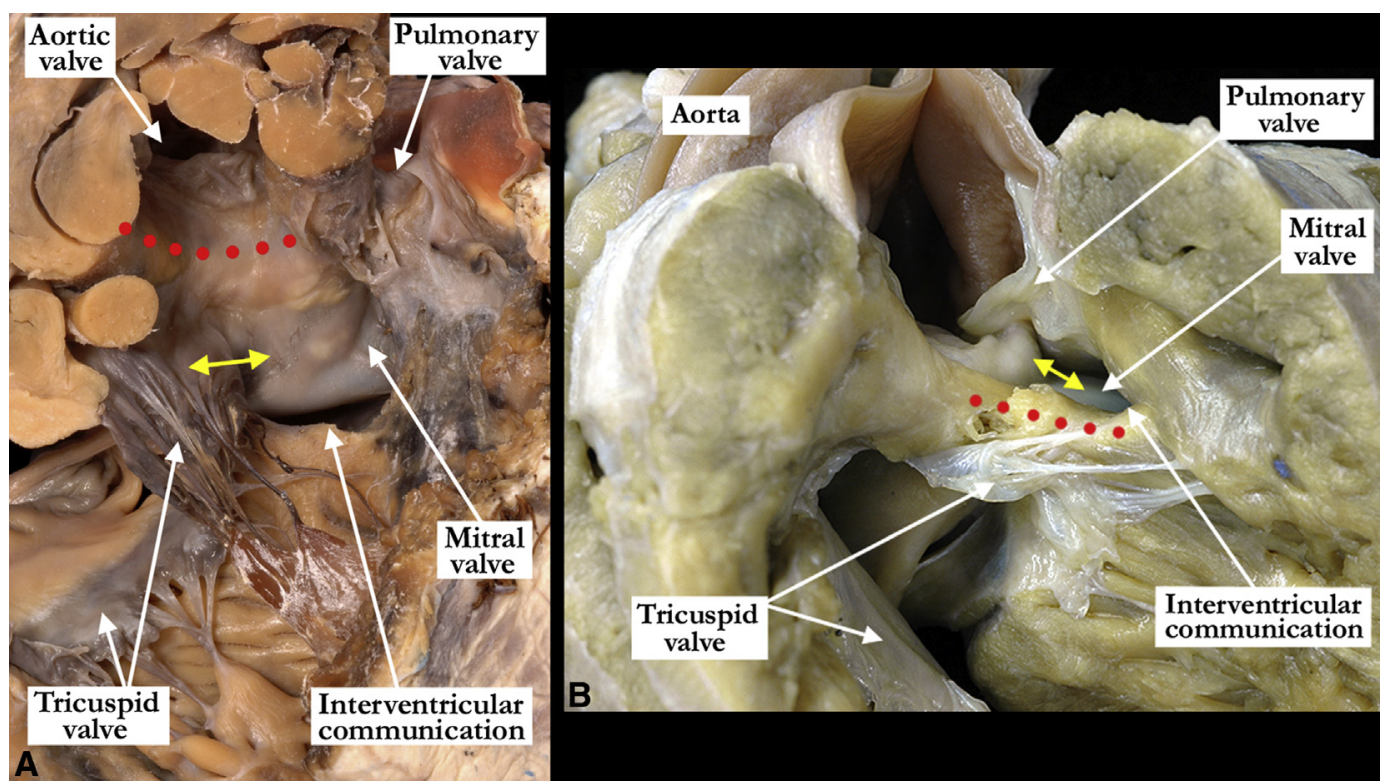

FIGURE 5. A, Heart with double-outlet right ventricle with bilateral infundibula and a subaortic interventricular communication. Despite the presence of the muscular inner heart curvature interposed between the leaflets of both arterial and both atrioventricular valves (red dotted lines), the defect itself is perimembranous because of the fibrous continuity between the leaflets of the tricuspid and mitral valves in its posteroinferior corner (double-headed yellow arrow). B, Heart with the interventricular communication in the subpulmonary position, with fibrous continuity in its roof between the leaflets of the pulmonary and mitral valves (double-headed yellow arrow). The defect itself, however, has a muscular posteroinferior rim (red dotted line) because of fusion of the caudal limb of the septomarginal trabeculation with the inner heart curvature and the muscular outlet septum.

atrioventricular conduction tissue (Figure 5, B). These latter interventricular communications, when viewed from their right ventricular aspect, had exclusively muscular borders. The cranial margin of the communication, however, was the inner heart curvature, or ventriculoinfundibular fold, rather than the muscular outlet septum (Figure 5, A). In all the hearts with DORV, the hole representing the exit from the left ventricle, or the geometric interventricular communication, is therefore a separate area from that extending from the crest of the apical muscular septum to the underside of the muscular outlet septum, or its fibrous remnant (Figure 6). It is this latter area that will be closed by the surgeon to place one or other arterial root in continuity with the cavity of the left ventricle, thus achieving potential biventricular surgical repair.

\section{DISCUSSION}

The criterion chosen by us to select the hearts studied from our various archives was origin of the greater parts of both arterial roots from the morphologically right ventricle. It was this feature that was emphasized by Neufeld and colleagues ${ }^{5,6}$ when they carried out their seminal studies of the hearts we now describe simply as having DORV. In the early years of pediatric cardiac surgery, however, it became conventional to consider bilateral infundibula, or coni, to be the defining feature of DORV. ${ }^{7}$ This approach was largely promoted to distinguish between tetralogy of Fallot and DORV at a time when surgical results for correction of these lesions varied significantly. Those who used this concept, however, failed to appreciate that, in the initial description provided by Fallot $^{8}$ of the hearts we now describe with his name, 1 of the 3 hearts examined was stated to have two-thirds of the overriding aortic valve supported by the right ventricle, whereas in a second heart, the aortic valve was described as arising exclusively from the right ventricle. Those who continue to use the presence of bilateral coni as the defining feature also fail to abide by the important principle subsequently established by Van Praagh and colleagues ${ }^{9}$ known as the morphologic method. This principle states that structures and complexes within the heart should be defined on the basis of their own intrinsic morphology rather than according to other features that are themselves variable. When considered relative to hearts with both arterial trunks arising from the right ventricle, the morphologic method therefore dictates that the ventriculoarterial connection should be the paramount defining feature rather than the presence or absence of conal muscle bilaterally. Indeed, had we chosen to use the criterion of bilateral coni in our own study, we would have been forced to exclude $77 \%$ of the hearts from consideration. The results of our study, furthermore, do not support the claim of Lacour-Gayet and associates, ${ }^{3}$ namely that the presence of a subaortic conus remains the major landmark of the anomaly. It is also of significance that Van Praagh's own 


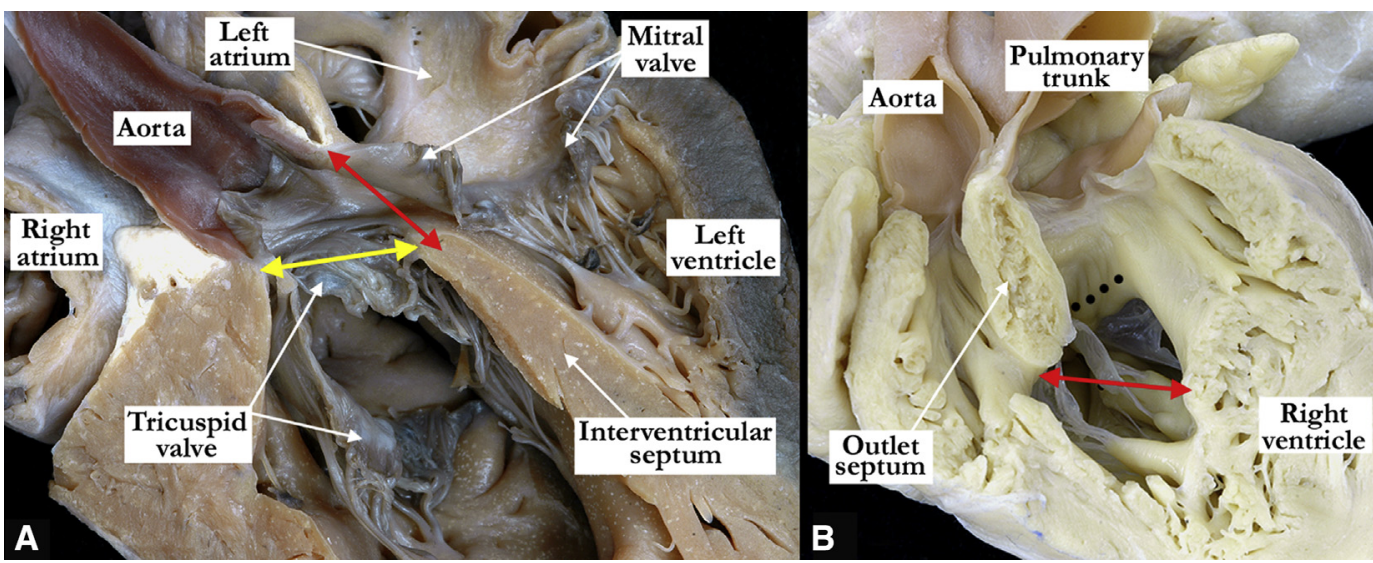

FIGURE 6. A, Heart cut in four-chamber fashion, incorporating the aortic root, which along with the pulmonary root is supported exclusively by the right ventricle. The interventricular communication (double-headed red arrow) is roofed by the inner heart curvature, which in this heart is fibrous. Note that there is fibrous continuity between the leaflets of the aortic valve and both atrioventricular valves. There is also fibrous continuity between the leaflets of the tricuspid and mitral valves, making the defect perimembranous. The double-headed yellow arrow indicates the area that would be closed by the surgeon to tunnel the aortic root into the left ventricle. It is this appearance that demonstrates so clearly the difference between the interventricular communication and the ventricular septal defect. B, The difference is further exemplified by a heart that has been windowed by removing the parietal wall of the right ventricle. The image shows how the plane of ventricular septation extends from the crest of the muscular ventricular septum to the underside of the muscular outlet septum. This is the channel that would be described as the ventricular septal defect in hearts with concordant or discordant ventriculoarterial connections (double-headed red arrow). The interventricular communication, in contrast, is roofed by the muscular inner heart curvature (black dotted line), with this heart having bilateral infundibula. There is fibrous continuity between the leaflets of the tricuspid and mitral valves, again making the defect perimembranous.

group now recognizes that DORV can exist in the absence of bilateral coni. ${ }^{10}$

Lacour-Gayet and colleagues ${ }^{3}$ also drew attention to the suggestion of Sidi and associates, ${ }^{11}$ namely that the group of hearts is better addressed in terms of arterial malposition rather than DORV. We are unable to offer any support for this notion. In the first place, hearts are also described as having arterial malposition when the arterial trunks arise in concordant fashion from the ventricular mass but with parallel rather than spiraling arrangement of the arterial trunks as they extend into the mediastinum. In the second place, in the diagram produced by Sidi and his associates ${ }^{11}$ to substantiate the concept of "malposition" as opposed to DORV, it is the inner heart curvature, or ventriculoinfundibular fold, that is incorrectly shown to represent the outlet septum. This important distinction is seemingly also not appreciated by all those who continue to describe the hole between the ventricles in the setting of DORV as the ventricular septal defect. Recognition of the difference between the area of deficient ventricular septation, as opposed to the geometric interventricular communication, can now serve to provide a pragmatic definition for DORV.

The essence of hearts with DORV, as it is for all those with overriding arterial valves, is that the muscular outlet septum, or its fibrous remnant, is no longer an interventricular structure. When the overriding is in favor of the right ventricle, then the outlet septum of necessity is a right ventricular structure. The area of deficient ventricular septation then extends from the crest of the apical muscular septum to the under surface of the outlet septum. This is the area along which the surgeon will place a patch to reconnect the overriding arterial valve with the cavity of the left ventricle. Because there is valvular overriding, it follows that the area of potential ventricular septation cannot be the same as the plane of geometric separation between the cavities of the two ventricles. This latter plane, which represents the true interventricular communication, is provided by continuing cranially the long axis of the muscular ventricular septum. By using the cord represented by this plane relative to the circumference of the overriding arterial root, it is possible accurately to assign the overriding arterial root to the ventricle supporting its greater part. It was this feature that we used when assigning the hearts currently studied to the category of DORV.

Of course, not all hearts with overriding arterial roots have the ventriculoarterial connection of DORV. When the greater part of the overriding arterial root is supported by the left ventricle, then the connection will be concordant when it is the aortic root that overrides or discordant in the setting of overriding of the pulmonary root. In these circumstances, when the surgeon approaches the hole between the ventricles from the right side, he or she will usually consider it possible simply to close the hole between the ventricles. In contrast, when the greater part of the overriding root is supported by the right ventricle, the surgeon approaching the hole between the ventricles from 
the right side will appreciate the need to use a tunnel-shaped patch rather than a flat patch. Recognition of this difference provides a pragmatic solution to defining DORV in the setting of overriding arterial roots.

It is, of course, also the case that in many hearts the entirety of both arterial roots is supported by the right ventricle. This is the arrangement described by Lacour-Gayet and colleagues ${ }^{3}$ as " $200 \%$ double outlet." Our analysis shows that such hearts can have bilateral coni but can also be found with fibrous continuity in the roof of the interventricular communication between the leaflets of the arterial and atrioventricular valves. Lacour-Gayet and associates ${ }^{3}$ have emphasized that many such hearts with $200 \%$ double outlet have the interventricular communication at a significant distance from the arterial roots. It was these lesions that were identified by Lev and colleagues ${ }^{4}$ as having noncommitted defects. In our series, the most obvious hearts with such noncommitted defects had common atrioventricular junctions. The interventricular communication, unequivocally between the ventricular inlets, was then part of an atrioventricular septal defect. Lacour-Gayet and colleagues $^{3}$ nonetheless have also emphasized that some channels between the ventricles in hearts with separate atrioventricular junctions can be distant from the arterial outlets. Whether these should also be considered noncommitted then becomes a judgment call. In some instances, valvular tension apparatus interposes between the defect and both arterial outlets. Such features can certainly then in a surgical sense make the defects noncommitted. In other circumstances, as emphasized by Lacour-Gayet and colleagues, ${ }^{3}$ such relatively distant holes can still be tunneled into one or other arterial outlet, thus rendering them surgically committed. In the past, we had presumed that such distant holes occupied the ventricular "inlet septum." We now realize that in reality there is no true inlet septum present, even in hearts with DORV. In all the hearts examined in this study that had separate atrioventricular junctions, a plane of cleavage existed between the medial leaflet of the mitral valve and the muscular ventricular septum. Thus, no part of the muscular septum interposes between the inlets of the right and left ventricles. The interventricular communication in such settings nonetheless can open into the inlet of the right ventricle.

In summary, our study has shown that, even in the setting of $200 \%$ double outlet, hearts can be found with fibrous continuity between the leaflets of the arterial and atrioventricular valves. More importantly, from the surgical stance, the channel between the ventricles is best described as the interventricular communication, because it does not correspond with the area of the putative ventricular septation.

\section{Conflict of Interest Statement}

Authors have nothing to disclose with regard to commercial support.

\section{References}

1. Wilcox BR, Ho SY, Macartney FJ, Becker AE, Gerlis LM, Anderson RH. Surgical anatomy of double-outlet right ventricle with situs solitus and atrioventricular concordance. J Thorac Cardiovasc Surg. 1981;82:405-17.

2. Walters HL III, Mavroudis C, Tchervenkov CI, Jacobs JP, Lacour-Gayet F, Jacobs ML. Congenital heart surgery nomenclature and database project: double outlet right ventricle. Ann Thorac Surg. 2000;69(Suppl 4):S249-63.

3. Lacour-Gayet F, Haun C, Ntalakoura K, Belli E, Houyel L, Marcsek P, et al. Biventricular repair of double outlet right ventricle with non-committed ventricular septal defect (VSD) by VSD rerouting to the pulmonary artery and arterial switch. Eur J Cardiothorac Surg. 2002;21:1042-8.

4. Lev M, Bharati S, Meng CC, Liberthson RR, Paul MH, Idriss F. A concept of double-outlet right ventricle. J Thorac Cardiovasc Surg. 1972;64:271-81.

5. Neufeld HN, Du Shane JW, Wood EH, Kirklin JW, Edwards JE. Origin of both great vessels from the right ventricle. I. Without pulmonary stenosis. Circulation. $1961 ; 23: 399-412$

6. Neufeld HN, Du Shane JW, Edwards JE. Origin of both great vessels from the right ventricle. II. With pulmonary stenosis. Circulation. 1961;23:603-12.

7. Baron MG. Radiologic notes in cardiology. Angiographic differentiation between tetralogy of Fallot and double-outlet right ventricle. Relationship of the mitral and aortic valves. Circulation. 1971;43:451-5.

8. Fallot A. Contribution à l'anatomie pathologique de la maladie bleue (cyanose cardiaque). Marseille Med. 1888;25:77-93. French.

9. Van Praagh R, David I, Wright GB, Van Praagh S. 1980 Large RV plus small LV is not single RV. Circulation. 1980;61:1057-8.

10. Ezon D, Goldberg JF, Kyle WB. Atlas of congenital heart disease: an illustrated guide to the Van Praagh and Anderson approaches to describing congenital cardiac pathology. Houston: Baylor College of Medicine, Texas Children's Hospital; 2015:79-84.

11. Sidi D, Vouhé P, Ou P. Chapter 44: transposition and malposition of the great arteries with ventricular septal defects. In: Moller JH, Hoffman JI, Benson DW, Van Hare GF, Wren C, eds. Pediatric cardiovascular medicine. 2nd ed. Oxford: Wiley-Blackwell; 2012:638-50.

Key Word: double-outlet right ventricle, interventricular communication, ventricular septal defect, malposition 